\title{
Flora do Ceará, Brasil: Krameriaceae
}

\author{
Flora of Ceará, Brazil: Krameriaceae
}

Sérgio Helano Barbosa Capistrano ${ }^{1} \&$ Maria Iracema Bezerra Loiola ${ }^{2,3}$

\begin{abstract}
Resumo
Este estudo consiste no levantamento florístico dos representantes de Krameriaceae no estado do Ceará, como parte do projeto "Flora do Ceará". O estudo foi baseado na análise comparativa dos caracteres morfológicos de espécimes depositados nos herbários EAC, HUEFS e UFRN, bibliografias especializadas, fotos de materiais-tipo, coletas e observações de campo. Foram registradas três espécies de Krameria: K. argentea, $K$. grandiflora e $K$. tomentosa. As espécies ocorrem preferencialmente em ambientes mais secos: $K$. argentea foi registrada no município do Crato em vegetação de cerrado (savana), e K. grandiflora em Morada Nova e Aracati em vegetação de caatinga (savana estépica); já K. tomentosa tem ampla distribuição e foi encontrada na restinga, cerrado e caatinga. Krameria grandiflora é nova ocorrência para o Ceará.
\end{abstract}

Palavras-chave: Diversidade, Krameria, nordeste do Brasil, neotrópicos.

\begin{abstract}
We present at floristic survey of Krameriaceae occurring in the Ceará state, as part of "Flora do Ceará" project. The study was based on the comparative analysis of morphological characters specimens of herbarium EAC, HUEFS and UFRN, specialized bibliographies, photo-type material, collections and field observations. Three species of Krameria were found: K. argentea, K. grandiflora and K. tomentosa. The species occur preferentially in drier habitats: $K$. argentea was recorded in the municipality of Crato in cerrado vegetation (savanna) and $K$. grandiflora in the municipalities of Morada Nova and Aracati in caatinga vegetation (stepic savanna); K. tomentosa has wider distribution and was found in restinga, cerrado and caatinga. Krameria grandiflora is new record for the Ceará state.
\end{abstract}

Key words: Diversity, Krameria, northeastern Brazil, Neotropics.

\section{Introdução}

Krameriaceae Dumort. está constituída por um único gênero, Krameria Loefl., que compreende 18 espécies com distribuição exclusivamente neotropical, sendo frequente em ambientes secos a sazonalmente secos (Simpson 2004). A maioria das espécies é encontrada no leste do México e na porção centro-leste do Brasil, nos Domínios Amazônia, Caatinga, Cerrado e Mata Atlântica, abaixo de $1.500 \mathrm{~m}$ de altitude (Every \& Baracat 2009).

Os representantes dessa família possuem hábito variável podendo ser arbustos, subarbustos ou ervas com folhas alternas, geralmente simples, raro trifolioladas; inflorescência racemosa terminal ou lateral, frequentemente reduzida a uma flor; flores zigomorfas, andróginas; cálice com quatro sépalas petaloides (duas laterais, uma superior e uma inferior); corola geralmente com cinco pétalas dimórficas, duas modificadas em glândulas secretoras de óleo (elaióforos), localizadas em cada lado do ovário e três reduzidas, inseridas junto à base da sépala superior; ovário súpero, bicarpelar; fruto do tipo núcula, geralmente recoberto por tricomas e/ou espinhos, com uma semente (Simpson 1989; Every \& Baracat 2009). Espécies de Krameria são citadas como hemiparasitas de raízes de algumas famílias (Asteraceae, Cactaceae, Poaceae, Portulaceae), sendo os haustórios observados tanto em seu ambiente natural com em cultivo em rizotron (Weigend \& Dostert 2008).

A posição sistemática e as afinidades de Krameriaceae têm apresentado divergências entre

\footnotetext{
${ }^{1}$ Universidade Federal do Ceará, Bolsista Jovens Talentos - IC, bl. 906, Campus do Pici, 60455-970, Fortaleza, CE, Brasil.

${ }^{2}$ Universidade Federal do Ceará, Depto. Biologia, Herbário Prisco Bezerra - EAC, bl. 906, Campus do Pici, 60455-970, Fortaleza, CE, Brasil.

${ }^{3}$ Autor para correspondência: iloiola@ufc.br
} 
os diferentes autores. O gênero Krameria foi proposto por Loefling em 1758. Jussieu (1789) considerou esse gênero com posição incerta. De Candolle (1824) associou Krameria à família Polygalaceae (Polygaleae), tratamento aceito posteriormente por Bentham \& Hooker (1862) e Baillon (1874). Já Dumortier (1829) propôs a família monotípica Krameriaceae, tratamento não aceito pelos demais botânicos da época. Posteriormente, Taubert (1892) posicionou Krameria em Fabaceae devido às flores zigomorfas e anteras com deiscência poricida. Benson (1957) sugeriu a criação da subfamília Kramerioideae em Leguminosae. Hutchinson (1959) e Cronquist (1988) reconheceram a pertinência da família monotípica Krameriaceae na ordem Polygalales. Atualmente, estudos baseados em dados moleculares sugerem o posicionamento de Krameriaceae em Zygophyllales (APG III 2009), clado Rosídeas, Fabídeas (Eurosídeas I).

Os principais estudos com representantes de Krameriaceae no Brasil foram realizados por Bennett (1874) que tratou seis espécies na Flora Brasiliensis, das quais duas eram novas para a ciência; Simpson (1989), que reconheceu 17 espécies de Krameria para a região Neotropical, e Simpson et al. (2004) que baseados em estudos moleculares (ITS 1, 5.8S e ITS 2), dados biogeográficos e morfologia discutiram as relações taxonômicas das 18 espécies de Krameria. Já Giannini et al. (2011) utilizaram a modelagem de nicho ecológico e ferramentas multivariadas para analisar aspectos ecológicos e geográficos de todos os representantes de Krameriaceae.

As espécies de Krameria são conhecidas popularmente no Ceará como carrapicho-deboi, carrapicho-de-cavalo, carrapicho-roxo, carrapicho-bravo e carrapicho. Algumas espécies do gênero possuem potencial econômico: as raízes de $K$. argentea Mart. são reconhecidas como adstringentes e usadas no tratamento de problemas intestinais (Braga 2001); já as raízes de K. lappacea (Dombey) Burdet \& Simpson e K. lanceolata Torrey são ricas em taninos e indicadas na Europa, América do Norte e América do Sul no tratamento de problemas intestinais e câncer; são também usadas na fabricação de dentifrícios e antissépticos bucais (Simpson 1989, 1991).

Para o Brasil foram registradas, até o momento, cinco espécies de Krameria nos domínios fitogeográficos Amazônia, Caatinga, Cerrado e Mata Atlântica (Simpson 2014).
Especificamente para o Ceará nenhum estudo taxonômico ou sobre distribuição dos representantes de Krameria foi realizado. Inserido no projeto "Flora do Ceará", o presente estudo tem como objetivo o levantamento florístico das espécies de Krameriaceae, contribuindo para um maior conhecimento e atualização da distribuição geográfica dos representantes dessa família.

\section{Material e Métodos}

O estudo baseou-se na análise comparativa de amostras obtidas em campo e em espécimes depositados nos Herbários EAC, HUEFS e UFRN, cujas siglas estão de acordo com Thiers (2014). As identificações foram realizadas com o auxílio de bibliografia especializada (Simpson 1989) e análise de imagens de coleções-tipo disponíveis no sítio dos Herbários F, K e NY. Os nomes dos autores foram baseados no sítio do IPNI (2014).

A terminologia para a descrição dos caracteres morfológicos seguiu Radford et al. (1974) e Stearn (1992). Já os dados referentes à forma de crescimento (hábito), hábitat, período de floração e frutificação e nome popular foram obtidos dos rótulos das exsicatas e/ou das observações em campo.

Os mapas de distribuição das espécies foram gerados através do programa DIVA-GIS (Hijmans et al. 2005). Quando as coordenadas geográficas associadas à localidade das coletas estavam ausentes nas etiquetas das exsicatas, utilizou-se as coordenadas do município obtidas a partir da ferramenta geoLoc (CRIA 2014). A classificação da vegetação foi feita utilizando-se os nomes locais e buscaram-se os termos correspondentes no Manual Técnico da Vegetação Brasileira (IBGE 2012).

\section{Resultados e Discussão}

Para o Ceará foram registradas três espécies de Krameria: $K$. argentea Mart. ex Spreng., K. tomentosa A.St.-Hil. e K. grandiflora A.St.-Hil. (Fig. 1), sendo esta última nova ocorrência para o estado, uma vez que a Lista de Espécies da Flora do Brasil (Simpson 2014), citou para o território cearense apenas Krameria tomentosa, e K. argentea foi registrada por Ribeiro-Silva et al. (2012) para a região do cariri cearense.

Além dos caracteres usados na chave de identificação, as espécies de Krameriaceae ocorrentes no Ceará podem ainda ser reconhecidas pelo conjunto de características apresentadas na Tabela 1. 


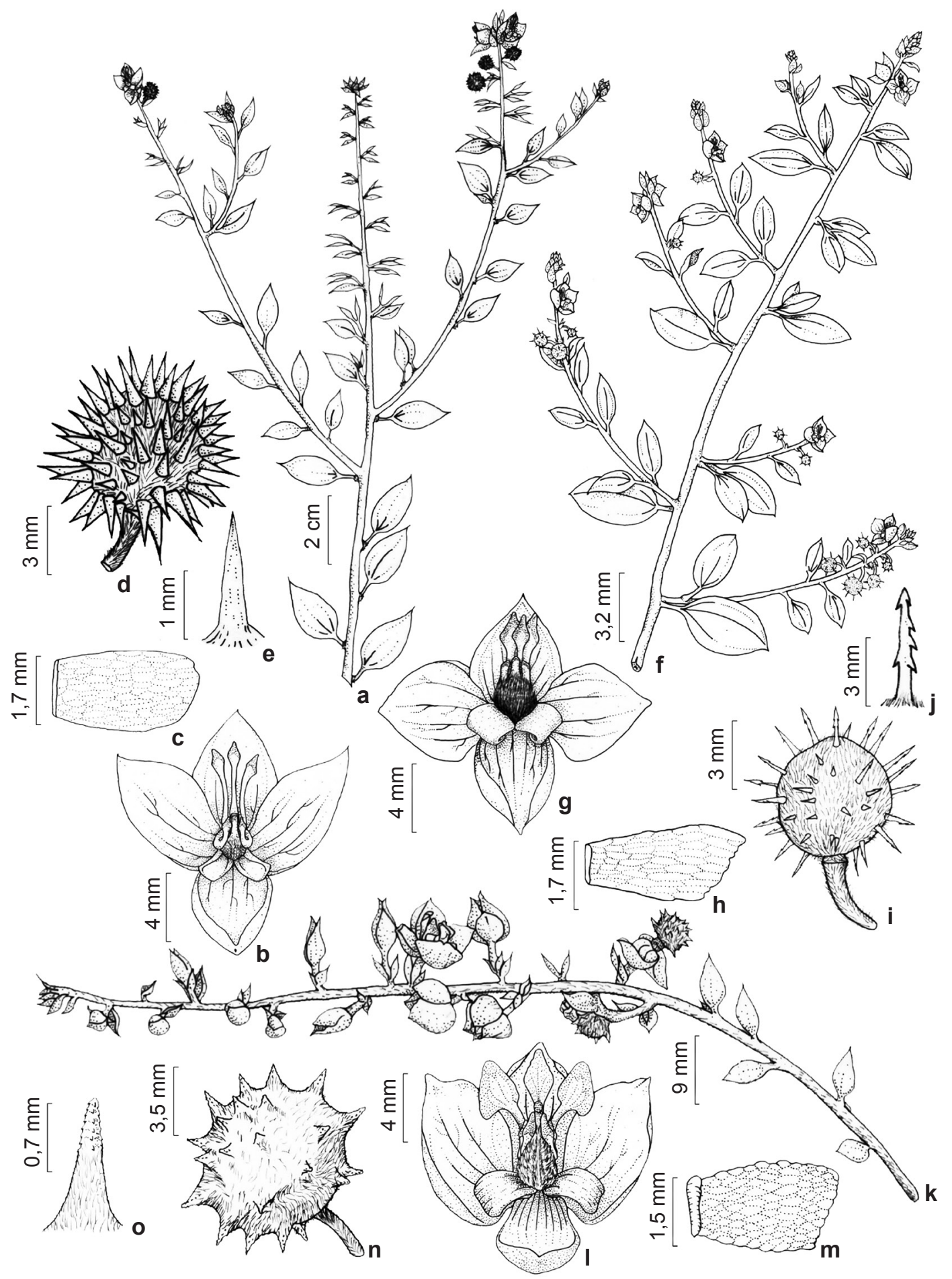

Figura 1 - a-e. Krameria argentea Mart. ex Spreng. - a. ramo florido; b. flor; c. elaióforo; d. fruto; e. fruto com espinho. f-j. Krameria grandiflora A.St.-Hil. - f. ramo florido; g. flor; h. elaióforo; i. fruto; j. fruto com espinho. k-o. Krameria tomentosa A.St.-Hil. - k. ramo florido; 1. flor; m. elaióforo; n. fruto; o. fruto com espinho.

Figure 1 - a-e. Krameria argentea Mart. ex Spreng.- a. flowering branch; b. flower; c. elaiophore; d. fruit; e. fruit spine. f-j. Krameria grandiflora A.St.-Hil. - f. flowering branch; g. flower; h. elaiophore; i. fruit; j. fruit spine. k-o. Krameria tomentosa A.St.-Hil. - k. flowering branch; 1. flower; m. elaiophore; $n$. fruit; o. fruit spine. 
Tabela 1 - Comparação dos caracteres morfológicos das espécies de Krameria registradas no Ceará. Table 1 - Morphological comparison of the species of Krameria registered in Ceará state.

\begin{tabular}{|c|c|c|c|}
\hline Característica & K. argentea & K. grandiflora & K. tomentosa \\
\hline Tipo de indumento & tomentoso a velutino & tomentoso a viloso & tomentosos a velutino \\
\hline Tamanho das folhas (mm) & $7-12 \times 17-20$ & $9-13 \times 3,0-6,0$ & $10-15 \times 20-27$ \\
\hline Forma das folhas & ovada a elíptica & lanceolada a ovada & elíptica \\
\hline Pecíolo (mm) & $3-5$ & $1,5-4$ & $4-8$ \\
\hline Pedicelo (mm) & $4-6$ & $6-8$ & $5-6$ \\
\hline Indumento do ovário & velutino & velutino & densamente velutino \\
\hline Tamanho do fruto & $4,0-6,5 \mathrm{~mm}$ & $5,0-6,0 \mathrm{~mm}$ & $4,5-6,5 \mathrm{~mm}$ \\
\hline Tamanho dos espinhos nos frutos (mm) & $1,0-2,5$ & $0,8-2,0$ & $2,5-5,0$ \\
\hline Cor dos espinhos & ferrugíneos a avermelhados & alaranjados a ferrugíneos & avermelhados a ferrugíneos \\
\hline
\end{tabular}

\section{Tratamento taxonômico}

Krameriaceae Dumort., Anal. Fam. Pl., p. 20. 1829, nom. cons.

Arbustos perenes, subarbustos ou ervas, às vezes hemiparasitas de raízes; indumento estrigoso, seríceo, tomentoso ou viloso nas porções vegetativas e reprodutivas. Folhas alternas, dísticas ou espiraladas, simples ou trifolioladas, lineares, lanceoladas, ou ovadas, com margem inteira, sésseis a pecioladas. Inflorescências terminais ou axilares, em panículas, racemos ou reduzidas a uma única flor. Flores andróginas, zigomorfas, 4-5meras, com pedúnculo e pedicelo separados por um par de bractéolas; cálice com 4 sépalas (duas laterais, uma superior e uma inferior), com face abaxial tomentosa a velutina e adaxial glabra; corola geralmente com 5 pétalas (raro 4), dimórficas, duas modificadas em glândulas secretoras de óleo (pétalas glandulares ou elaióforos) e localizadas em ambos os lados do ovário, três reduzidas, com porção terminal expandida ou não, livres, ligeiramente fundidas na base ou conatas até $75 \%$ dos seus comprimentos; estames 3-4, livres ou unidos na base, inseridos na base das pétalas reduzidas, anteras rimosas ou poricidas; gineceu apocárpico; ovário súpero, bicarpelar (ou unicarpelar pela atrofia de um dos carpelos), glabro a hirsuto; estilete 1, geralmente arqueado; estigma 1; óvulo 1, anátropo. Fruto núcula, globoso ou cordiforme, geralmente recoberto por tricomas (velutino ou tomentoso) e espinhos, gloquídeos presentes ou não; semente 1 , frequentemente sem endosperma.

\section{Chave de identificação para as espécies de Krameria ocorrentes no Ceará}

1. Erva prostrada; bractéolas 3; inflorescências ao longo dos ramos terminais; espinhos do fruto com tricomas velutinos

K. grandiflora

1. Subarbusto a arbusto ereto; bractéolas 2; inflorescências nas porções terminais dos ramos; espinhos do fruto glabros.

2. Folhas com nervuras proeminentes na face abaxial; flores congestas; frutos levemente velutinos; espinhos do fruto 1-2,5 mm, espessados, adensados; gloquídeos ausentes K. argentea

2. Folhas com nervuras pouco evidentes na face abaxial; flores esparsas; frutos densamente tomentosos; espinhos do fruto 2,5-5mm, delgados, esparsos; gloquídeos presentes

K. tomentosa

1. Krameria argentea Mart. ex Spreng., Syst. Veg. (ed. 16) 2: 844. 1825.

Fig. 1 a-e; 2

Subarbusto a arbusto ereto, $20-40 \mathrm{~cm}$

alt., pouco ramificado; recoberto por indumento tomentoso a velutino. Folhas 17-25 × 7-12 mm, lâmina ovada a elíptica, ápice acuminado, apiculado, base atenuada; venação acródroma imperfeita basal, com nervuras proeminentes na face abaxial; pecíolo 3-5 $\mathrm{mm}$. Inflorescências $2-5 \mathrm{~cm}$ compr., nas porções terminais dos ramos, flores congestas. Flores róseo-vináceas, subtendidas por 2 bractéolas com 4-5 × 1-1,2 mm, lineares a lanceoladas, 
apiculadas; pedicelo 4-6 $\mathrm{mm}$; sépalas laterais ca. 2,7 × 4,5 mm, elípticas; sépala superior ca. 8,5 ×4 $\mathrm{mm}$, ovada; sépala inferior ca. $8 \times 5 \mathrm{~mm}$, elíptica; pétalas reduzidas 3 , ca. $5 \times 1 \mathrm{~mm}$, lineares, com porção terminal levemente expandida, glabras, livres ou ligeiramente unidas na base; pétalas glandulares (elaióforos) 2, ca. $4 \times 2 \mathrm{~mm}$, oblongas, glabras, face abaxial rugosa, com glândulas oleíferas alongadas, orientadas paralelamente, margem ligeiramente denteada, face adaxial lisa; estames 4, didínamos, filetes maiores 5-10 mm, filetes menores 4,5-8mm; ovário $3 \mathrm{~mm}$ diâm., ovoide, velutino; estilete 3 mm. Frutos 4-6,5 mm diâm., globosos, levemente velutinos, verde-claro quando imaturos, densamente espinhosos; espinhos ca. 1-2,5 mm, espessados, adensados, quase se tocando na base, glabros, ferrugíneos a avermelhados; gloquídeos ausentes. Sementes 5,5 mm diâm., esféricas a ovoides.

Material examinado: Crato, 31.III.1985, fl., fr., $A$. Fernandes s.n. (EAC 13094); idem, Barreiro Grande, FLONA, 10.V.2000, fl., F.S. Cavalcanti 762 (EAC).

Material examinado adicional: Piauí: Bom Jesus do Gurguéia, 22.VII.1983, fl., fr., A. Fernandes (EAC 12115); Pernambuco: Moreilândia, fl., E.R. Silveira (EAC 23057).

De acordo com Simpson (1989, 2014), Krameria argentea é uma espécie endêmica do Brasil, ocorrendo nas regiões Norte (Tocantins), Nordeste (Bahia, Piauí), Centro-Oeste (Distrito Federal, Goiás) e Sudeste (Minas Gerais) sempre associada ao domínio do cerrado. Tem ocorrência rara no Ceará e parece preferir substratos sedimentares lateríticos, tendo registro apenas no sul do estado do Ceará (Fig. 2), na chapada do Araripe. Coletada com flores em março e maio e com frutos em maio. Conhecida popularmente como "carrapicho-de-boi".

2. Krameria grandiflora A.St.-Hil., Ann. Soc. Royale Sci., Belles-Lettres et Ars d'Orléans. Mém. Sér. 2. 9:18. 1828.

Fig. $1 \mathrm{f}-\mathrm{j} ; 2$

Erva prostrada, até $35 \mathrm{~cm}$ alt., pouco ramificada; ramos procumbentes com até $1 \mathrm{~m}$ compr.; indumento variando de tomentoso a viloso. Folhas 9-18 × 3-6 mm, lâmina lanceolada a ovada, ápice acuminado, apiculado, base atenuada; venação acródroma imperfeita basal, com nervuras pouco ou não visíveis na face abaxial; pecíolo 1,5-4 $\mathrm{mm}$. Inflorescências 5-11 cm compr., ao longo dos ramos terminais, flores esparsas. Flores vináceas, subtendidas por 3 bractéolas $1,5-7 \times 0,4-1 \mathrm{~mm}$, lanceoladas, apiculadas; pedicelo 6-8 $\mathrm{mm}$; sépalas laterais ca.
$9 \times 6 \mathrm{~mm}$, obovadas; sépala superior ca. 7,5 × 5 $\mathrm{mm}$, ovada; sépala inferior ca. $8 \times 6 \mathrm{~mm}$, ovada; pétalas reduzidas 3 , com $7-11 \times 1,2-1,5 \mathrm{~mm}$, lineares, ápice subcordado, glabras, concrescidas na base; pétalas glandulares (elaióforos) 2, com 2,5-4 × 2,5-3,5 mm, oblongas, glabras, face abaxial rugosa, com glândulas oleíferas alongadas, orientadas paralelamente, margem inteira, face adaxial lisa; estames 4 , didínamos, filetes maiores 4-5 mm, filetes menores 3-4 mm; ovário 2-3 mm diâm., ovoide, velutino; estilete 3-3,5 $\mathrm{mm}$. Frutos 5-6 mm diâm., cordiformes a globosos, verde claro quando imaturos, amarronzados na maturidade, densamente velutinos, espinhos esparsos, alaranjados ou ferrugíneos, 0,8-2 mm compr., com tricomas velutinos ao longo de todo o comprimento; gloquídeos presentes. Sementes ca. 4 mm diâm., ovoides.

Material examinado: Aracati, localidade Aroeiras, Fazenda Recordações, 03.II.2013, fl., fr., M.I.B. Loiola \& M. Loiola 2496 (EAC); Morada Nova, Sítio Boa Vista, 04.II.2014, fl., fr., J.A.A. Oliveira 01 (EAC).

Material examinado adicional: Bahia: Camaçari, rodovia Linha Verde, próximo de Arembepe, 17.VIII.1995, fl., G. Hatschbach et al. 63079 (HUEFS); Piauí: Brasileira, estrada para Piracuruca, 44'40"S, 41\%45'16"W, 15.III.2005, fl., J.G.A. de Nascimento et al. 439 (HUEFS); Rio Grande do Norte: Serra Negra do Norte, Estação Ecológica do Seridó, 08.III.2006, fl., R.T. Queiroz 626 (EAC, UFRN).

Esta espécie ocorre no Brasil e Paraguai (Simpson 1989). De acordo com Simpson (2014) foi registrada em quatro regiões brasileiras: Norte (Tocantins), Nordeste (Bahia, Maranhão, Paraíba, Piauí), Centro-Oeste (Distrito Federal, Goiás, Mato Grosso do Sul, Mato Grosso) e Sudeste (Espírito Santo, Minas Gerais) nos domínios fitogeográficos Amazônia, Cerrado, Caatinga e Mata Atlântica em vegetação de restinga, campo rupestre, cerrado e caatinga, em altitudes variando de 40 a 745m. No território cearense foi coletada apenas nos municípios de Morada Nova e Aracati em vegetação de caatinga (savana estépica). Vale ressaltar que em Aracati esta espécie foi encontrada desenvolvendo-se em solos arenosos. Coletada com flores e frutos em fevereiro. Conhecida popularmente como "carrapicho".

3. Krameria tomentosa A. St.-Hil., Ann. Soc. Royale Sci., Belles-Lettres et Ars d'Orléans. Mém. Sér. 2. 9:18. 1828.

Fig. 1k-o; 2

Subarbusto a arbusto ereto, até 1,2 m alt., densamente ramificado; ramos abertos, recobertos 


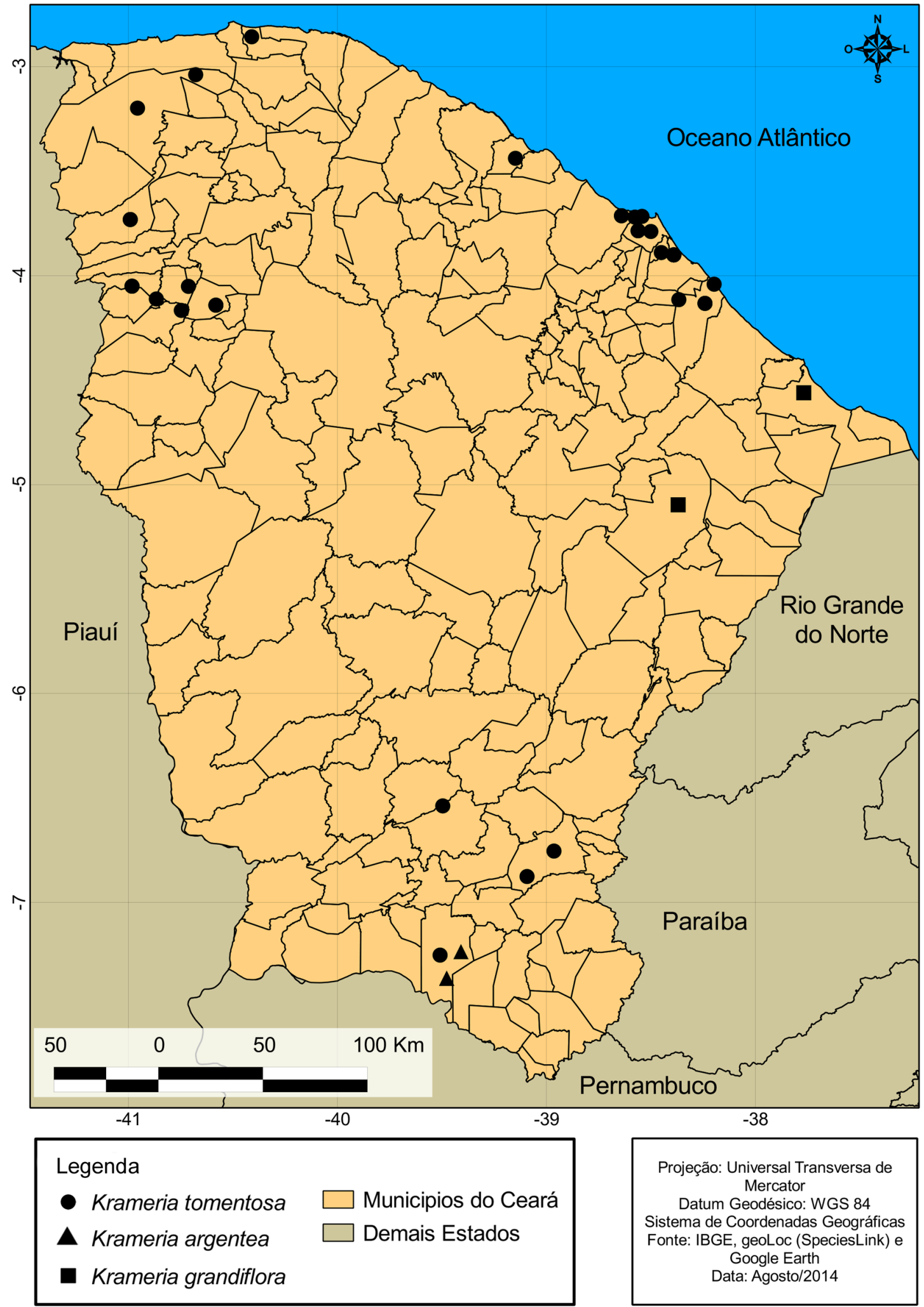

Figura 2 -Distribuição de Krameriaceae no Ceará, Brasil: $\$ Krameria argentea; $\mathbf{\square}$ Krameria grandiflora; $\bullet$ Krameria tomentosa. Figure 2 - Distribution of Krameriaceae in Ceará state, Brasil: Krameria argentea; $\mathbf{\square}$ Krameria grandiflora; $\bullet$ Krameria tomentosa. 
por indumento tomentoso a velutino. Folhas 20-27 × 10-15 mm, lâmina elíptica, ápice acuminado, apiculado, base atenuada; venação acródroma imperfeita basal, com nervuras pouco evidentes na face abaxial; pecíolo 4-8 $\mathrm{mm}$. Inflorescências 1-4 cm compr., nas porções terminais dos ramos, flores esparsas. Flores róseo-vináceas, subtendidas por 2 bractéolas, ca. $2 \times 1 \mathrm{~mm}$, lineares, apiculadas; pedicelo 5-6 mm; sépalas laterais 2,4-7 × 4-4,5 $\mathrm{mm}$, ovadas; sépala superior $8,5 \times 4 \mathrm{~mm}$, ovada; sépala inferior, $4 \times 2 \mathrm{~mm}$, elíptica; pétalas reduzidas 3 , com 3-4 ×0,8-1 mm, lineares, com ápice deltoide, variavelmente concrescidas na base, glabras; pétalas glandulares (elaióforos) 2, com 3,6-4 × 1,8-2 mm, transversalmente oblongas, glabras, face abaxial rugosa, recoberta por glândulas delgadas, alongadas e orientadas paralelamente, margem crenada, face adaxial lisa; estames 4, didínamos, filetes maiores 4-5,5 $\mathrm{mm}$, filetes menores $3,8-4,5 \mathrm{~mm}$; ovário 2-3 mm diâm., ovoide, densamente velutino; estilete 3-4 mm, glabro; Frutos 4,5-6,5 mm diâm., globosos, densamente tomentosos, espinhos esparsos; espinhos 2,5-5 mm, delgados, glabros, avermelhados a ferrugíneos; gloquídeos presentes. Sementes 5-6 mm diâm., esféricas a ovoides. Material examinado: Aquiraz, CEAC, 0350'20"S, 38 25'15"W, 21.III.2014, fl., M.I.B. Loiola \& S.H. Capistrano (EAC 56081); Cascavel, Águas Belas, 23.IV.1999, fl., fr., M.S. Lopes \& G.F. Mariz (EAC 27707); Caucaia, Parque Botânico do Ceará, 25.05.1998., fl., J.C.G. Paiva (EAC 26449); Eusébio, Pucaba/ Mangabeira, 20.V.2002, fl., fr., A.S.F. Castro (EAC 31725); Horizonte, Barra, 0406'56'S, 38 $22^{\circ} 00^{\prime \prime} \mathrm{W}$, 28.X.1999, fr., A.V. Vieira (EAC 33761); Pacujá, Serrinha, 0403'07'S, 4042'48'W, 27.III.2012, fl., E.M. Marreira et al. 257 (EAC); Paraipaba, APA Dunas de Lagoinha, 19.X.2003, fl., fr., Djane (EAC 33017); Reriutaba, Oitizeira, $2 \mathrm{~km}$ de Reriutaba a direita, 14.XI.2002, fl., F.S. Cavalacanti (EAC 32231); São Gonçalo do Amarante, Pecém, terreno da Ypióca, 11.XI.2007, fl., M.O.T. Menezes et al. 17 (EAC); Soledade, 02.03.2001, fl., A. Fernandes (EAC 30472); Tianguá, Santa Rita,23.VIII.2004, fl., L.W. Lima-Verde et al. 3026 (EAC).

Em território brasileiro, segundo Simpson (2014) esta espécie tem registro nas regiões: Norte (Amazonas, Pará, Tocantins), Nordeste (Alagoas, Bahia, Ceará, Maranhão, Paraíba, Pernambuco, Piauí, Rio Grande do Norte, Sergipe), CentroOeste (Goiás, Mato Grosso do Sul, Mato Grosso) e Sudeste (Minas Gerais, Rio de Janeiro). Ocorre nos domínios Amazônia, Caatinga, Cerrado e Mata Atlântica nos mais variados tipos de vegetação (caatinga (stricto sensu), campo rupestre, carrasco, cerrado (lato sensu), floresta ciliar ou galeria, floresta estacional decidual, floresta ombrófila, restinga e savana amazônica). No Ceará é a espécie que apresenta a mais ampla distribuição (Fig. 2). Foi registrada nos tabuleiros costeiros em restinga, no cerrado (savana) e na caatinga (savana estépica), sendo frequentemente associada a ambientes com solos arenosos. Aparentemente produz flores e frutos durante todo o ano. Conhecida popularmente como "carrapicho-de-cavalo", "carrapicho-roxo", "carrapicho-bravo" e "carrapicho".

\section{Agradecimentos}

À CAPES, a bolsa Jovens Talentos - IC concedida ao primeiro autor; aos Projetos INCT - Flora Virtual de Plantas e Fungos, SISBIOTA, ambos coordenados pela profa. Dra. Leonor Costa Maia/UFPE, o apoio financeiro para as coletas de campo; a Guilherme Rodrigues, a elaboração das ilustrações e a Régis Barbosa, a elaboração do mapa de distribuição das espécies.

\section{Referências}

Angiosperm Phylogeny Group III. 2009. An update of the Angiosperm Phylogenetic Group classification for the orders and families of flowering plants: APG III. Botanical Journal of the Linnean Society 161: 105-121.

Baillon, H. 1874. Polygalacées. Historie des plantes 5: 71-92.

Bennett, A.G. 1874. Polygalaceae. Krameriaceae. In: Martius, C.F.P. von; Eichler, A.W. \& Urban, I. Flora brasiliensis. München, Wien, Leipzig. Vol. 13, pp. 69-73.

Benson, L. 1957. Plant classification. Health and Co., Boston, Massachusetts. 688p.

Bentham, G. \& Hooker, J.D. 1862. Polygaleae. Genera plantarum 1: 134-140.

Braga, R. 2001. Plantas do nordeste, especialmente do Ceará. Coleção Mossoroense, série C. Vol. 1204. Fundação Guimarães Ducke/ Fundação Vingt-um Rosado, Mossosró. 164p.

CRIA. 2014. Geoloc. Disponível em < http://splink.cria. org.br/>. Acesso em 5 setembro 2014.

Cronquist, A. 1988. The evolution and classification of flowering plants. $2^{\mathrm{a}}$ ed. The New York Botanical Garden, New York. 555p.

De Candolle, A.P. 1824. Krameria. Prodromus 1: 14.

Dumortier, B.C.J. 1829. Krameriaceae. Analyse des families des plantes. Paris, Tournay. 23p.

Every, J.L.R. \& Baracat, A. 2009. Neotropical Krameriaceae. In: Milliken, W.; Klitgård, B. \& Baracat, A. Neotropikey - Interactive key and 
information resources for flowering plants of the Neotropics. Disponível em <http://www.kew. org/science/tropamerica/neotropikey/families/ Krameriaceae.htm>. Acesso em 30 setembro 2014.

Jussieu, A. L. 1789. Genera plantarum secundum ordines naturales disposita. Herissant and Barrois, Paris. $425 \mathrm{p}$.

Giannini, T.C.; Takahasi, A.; Medeiros, M.C.M.P.; Saraiva, A.M. \& Santos, I.A. 2011. Ecological niche modeling and principal component analysis of Krameria Loefl. (Krameriaceae). Journal of Arid Environments 75: 870-872.

Hijmans, R.J.L.; Guarino, A.; Jarvis, R.; O'Brien, P.; Mathur, C.; Bussink, M.; Cruz, I. Barrantes, \& Rojas. E. 2005. DIVA-GIS. Ver. 5.2. Disponível em $<$ http:diva-gis.org. > . Acesso em 20 outubro 2014.

Hutchinson, J. 1959. The families of flowering plants. $2^{\text {a }}$ ed. Vol. 1. Claredon Press, Oxford. 510p.

IBGE. 2012. Manual técnico da vegetação brasileira. $2^{\text {a }}$ ed. Disponível em <ftp://geoftp.ibge.gov.br/ documentos/recursos_naturais/manuais_tecnicos/ manual_tecnico_vegetacao_brasileira.pdf $>$. Acesso em 16 agosto 2014 .

IPNI. 2014. The International Plant Names Index. Disponível em <http://www.ipni.org $>$. Acesso em 3 agosto 2014.

Loefling, P. 1758. Iter hispanicum. Lars Salvii Kostnad, Stockholm. 195p.

Radford, A.E.; Dickson, W.C.; Massey, J.R. \& Bell, C.R. 1974. Vascular plant systematics. Harper \& Row, New York. 891p.

Ribeiro-Silva, S.; Medeiros, M.B.; Gomes, B.M.; Seixas, E.N.C. \& Silva, M.A.P. 2012. Angiospermas from the Araripe Nacional Forest, Ceará, Brazil. Check List 8: 744-751.

Simpson, B.B. 1989. Krameriaceae. Flora Neotropica Monograph. Vol. 49. New York Botanical Garden, New York. 88p.

Simpson, B.B. 1991. The past and present uses of Ratany (Krameria, Krameriaceae). Economic Botany 43: 397-409.

Simpson, B.B.; Weeks, A.; Helfgott, D.M. \& Larkin, L.L. 2004. Species relationships in Krameria (Krameriaceae) based on ITS sequences and morphology: implications for character utility and biogeography. Systematic Botany 29: 97-108.

Simpson, B. 2014. Krameriaceae. In: Lista de Espécies da Flora do Brasil. Jardim Botânico do Rio de Janeiro. Disponível em $<$ http://floradobrasil.jbrj.gov.br/jabot/ floradobrasil/FB140>. Acesso em 11 agosto 2014.

Stearn, W.T. 1992. Botanical Latin. $4^{\mathrm{a}}$ ed. David \& Charles Book, Redwood Press. England Ltd., London. 546p.

Taubert, P. 1892. Leguminosae. II. 6. CaesalpinioideaeKramerieae. In: Engler, A. \& Prantl, K. Die natürlichen Pflanzenfamilien. Vol. 3. W. Engelmann, Leipzig. Pp. 166-168.

Thiers, B. [continuously updated]. Index Herbariorum: A global directory of public herbaria and associated staff. New York Botanical Garden's Virtual Herbarium. Disponível em $<$ http://sweetgum.nybg. org/ih/> . Acesso em 28 setembro 2014.

Weigend, M. \& Dostert, N. 2008. Manejo sustentable de ratania en Perú: Krameria lappacea (Dombey) \& Simpson. Disponível em <http://www.botconsult. com/downloads/Ratanhia_Peru_2008.pdf $>$. Acesso em 25 outubro 2014. 